Chapman University

Chapman University Digital Commons

ESI Working Papers

Economic Science Institute

8-2-2017

\title{
How Product Innovation Can Affect Price Collusion
}

Andrew Smyth

Chapman University, smyth@chapman.edu

Follow this and additional works at: https://digitalcommons.chapman.edu/esi_working_papers

Part of the Econometrics Commons, Economic Theory Commons, and the Other Economics Commons

\section{Recommended Citation}

Smyth, A. (2017). How product innovation can affect price collusion. ESI Working Paper 17-26. Retrieved from https://digitalcommons.chapman.edu/esi_working_papers/239

This Article is brought to you for free and open access by the Economic Science Institute at Chapman University Digital Commons. It has been accepted for inclusion in ESI Working Papers by an authorized administrator of Chapman University Digital Commons. For more information, please contact laughtin@chapman.edu. 


\section{How Product Innovation Can Affect Price Collusion}

\section{Comments}

Working Paper 17-26 


\title{
How Product Innovation Can Affect Price Collusion*
}

\author{
Andrew Smyth ${ }^{\dagger}$
}

August 2, 2017

\begin{abstract}
Price conspiracies appear endemic in many markets. This paper conjectures that low expected returns from product innovation can affect price collusion in certain markets. This conjecture is tested - and supported-by both archival and experimental data. In particular, average market prices in low innovation experiments are significantly greater than those in high innovation, but otherwise identical experiments, because price collusion is more successful in the low innovation experiments.
\end{abstract}

Keywords: price collusion, product innovation, antitrust, experimental economics

JEL: L410, L100, O330, C920

\footnotetext{
* I am grateful to the Michael J. Piette Fellowship and the Economic Science Institute for funding. I thank Mark Isaac, Gary Fournier, Cortney Rodet, Bart Wilson, and seminar participants at Florida State, Chapman, Marquette, Massachusetts Amherst, and the London Experimental Workshop for helpful comments. Naturally, any errors are my own.

${ }^{\dagger}$ Department of Economics, Marquette University, Milwaukee, WI 53201, email: andrew.smyth@marquette.edu
} 


\section{Introduction}

"[W]e're not competing with a unique article here. Our bags and boxes aren't really any better or worse than those of our competitors... The only way to get a buyer is to sell at a lower price. Thus competitors may think that the only way to make it is to get together and fix prices."

- Folding box executive who participated in a price conspiracy (quoted in Sonnenfeld and Lawrence, 1978)

There are price conspiracies in some markets (school milk, concrete, paper products) year after year and even decade after decade. These markets typically lack 'killer' products that "confer market leadership and thus diminish or eliminate actual or potential rivals" (Evans and Schmalensee, 2002). This paper considers price conspiracies in markets where firms face not a perennial gale of creative destruction brought on by killer new products, but the chronic doldrums of technological stasis.

Given its illegality, firms are less likely to attempt price collusion in markets where they can use product innovation to soften or escape competition. As Wallace (1937) comments: "[W]here there is a large field for profitable development of new variations of the basic product, it seems unlikely that oligopolists would follow policies appropriate to more or less permanent division of the market in fixed proportions." However, in markets where product innovation appears unlikely to generate "sufficient" expected returns, firms may turn to price manipulation as an alternative avenue to supra-competitive profit.

There are two reasons why the expected return from product innovation may be low. First, either the ex ante size of the return from innovation may be low, or the probability of successfully innovating may be low, or both may be true. Second, successful innovators may not actually obtain much of the return from innovation ex post (appropriability may be low). This paper focuses on the first reason and posits that, ceteris paribus, price conspiracies are most likely in markets where the ex ante expected return from product 
innovation is low. ${ }^{1}$

I test the conjecture that the expected return from product innovation affects price collusion with both archival and experimental data. I first analyze cross-industry data collected from antitrust case reports and an industry-level accounting survey. If the conjecture is correct, collusion and innovation should be inversely related. While I estimate a significant, inverse relationship between price collusion and $R \& D$ intensity, the archival data cannot establish causation from the expected return from innovation to collusion: The inverse relationship I report in the data may stem from collusion affecting the amount of innovation attempted.

To better examine the possible causal link from the expected return from product innovation to price collusion, I also report data from laboratory experiments where subjects repeatedly make "product innovation" and pricing decisions. The experimental treatments differ only in the expected return from product innovation, and so mimic two very different markets: "high innovation" markets where firms frequently develop highly-differentiated new products and "low innovation" markets where firms almost always sell a homogeneous product.

While the empirical price fixing literature finds that collusive markets are usually characterized by product homogeneity, this consensus is not shared by the theoretical literature. $^{2}$ When product differentiation is modeled horizontally, it typically helps collusion, but when it is modeled vertically it usually hinders collusion. ${ }^{3}$ Moreover, when collusive coordination is assumed to be costly, product differentiation either aids or frustrates collusion

\footnotetext{
${ }^{1}$ Other important alternatives to price collusion for firms in markets with low expected returns from product innovation include cost innovation and merger.

${ }^{2}$ See Hay and Kelley (1974), Asch and Seneca (1975), Fraas and Greer (1977), Scherer and Ross (1990), Dick (1996), Symeonidis (2003), and Levenstein and Suslow (2006).

${ }^{3}$ See, for example, Häckner (1994). Symeonedis (1999) presents a vertical differentiation model suggesting that collusion is less stable in more $R \& D$ intensive industries.
} 
depending on the specific assumptions of the particular model. ${ }^{4}$

In this paper, product innovation (and thus differentiation) is incorporated into experiments in a novel way that is neither classically horizontal nor vertical. Innovation is both a function of an exogenous parameter and of subjects' endogenous decisions. Innovation success results in perfect product differentiation, whereas innovation failure means perfect product homogeneity. To explore the expected return from product innovation's effect on price collusion, the experimental design varies the exogenous innovation parameter across treatments - holding all else constant.

By design there are no predicted price differences between the high innovation and low innovation treatments, yet observed prices in the low innovation treatment are significantly greater than those in the high innovation treatments. The data show that subjects in the low innovation treatment are better at maintaining supra-competitive prices than their high innovation counterparts. Moreover, while collusive success is affected by the exogenouslydetermined expected return from innovation, collusive success does not affect innovation expenditure, so the price result is driven by treatment.

This paper suggests that product homogeneity not only explains collusive success, but that it also explains why certain markets are prone to collusion. Its empirical results support the conjecture that collusion may be perceived as the "only way to make it" in markets with low expected returns from innovation. In the next section, I analyze the archival data. In Section 3, I outline the experimental design, calculate price and innovation benchmarks for the experiments, and report and discuss the experimental data. Section 4 concludes the paper.

\footnotetext{
${ }^{4}$ See Thomadsen and Rhee (2007) and Colombo (2013).
} 


\section{Archival Evidence}

If the conjecture that the expected return from product innovation affects price collusion is correct, then price collusion should be inversely related to the expected return from product innovation in empirical data. This section uses archival data, and in particular R\&D intensity as a proxy for the expected return from product innovation, to test the conjecture. ${ }^{5}$ The data come primarily from Commerce Clearing House Trade Cases books for the years 1972-1982 and from the Federal Trade Commission's Annual Line of Business (LOB) Report for $1977 .{ }^{6}$ The sample period was chosen as a ten year span, centered on 1977. The unit of analysis is an industry as defined by a Standard Industry Classification (SIC) code.

To create a sample of price conspiracies, all citations listed in the indices of the Trade Cases books under 'price fixing' were examined and included in the sample if the conspiracy was horizontal and took place in a manufacturing industry (in order to match the LOB data that primarily cover manufacturing industries). Table 10 in Appendix I lists the final sample, which totals 50 conspiracies. 37 of the $50(74 \%)$ occurred in industries with below-average R\&D intensity, as calculated from the LOB data. ${ }^{7}$ A robust rank order (Flinger-Policello) test concludes that the mean of the distribution of R\&D intensities for collusive industries is lower than the corresponding mean for non-collusive industries $(U=1.86, p=0.032$, one-tailed $){ }^{8}$

Table 1 gives estimation results for two Probit specifications. ${ }^{9}$ The variable Collusion is

\footnotetext{
${ }^{5} \mathrm{R} \& \mathrm{D}$ intensity is used as a proxy variable in the spirit of Sutton (1998), who notes: "If R\&D spending is ineffective in raising consumers' willingness-to-pay for the firm's products, it can be shown that R\&D intensity is necessarily low."

${ }^{6}$ On the use of LOB data, see Scherer, et al. (1987) and Ravenscraft and Wagner (1991).

${ }^{7}$ This assumes that R\&D intensity in the ready-mix concrete industry is below average - a safe assumption. Of the 220 industries in the LOB data for which R\&D intensity can be calculated, $140(64 \%)$ have below average $R \& D$ intensity.

${ }^{8} \mathrm{~A}$ t-test accounting for unequal variance concludes the same thing $(t=2.57, p=0.006$, one-tailed).

${ }^{9}$ Note that these are Probit coefficient estimates and not marginal effects. Because the LOB report
} 
Table 1:

Probit Estimates

\begin{tabular}{lcc}
\hline Dependent variable: & \multicolumn{2}{c}{ Collusion } \\
& $(1)$ & $(2)$ \\
\hline Constant & $-2.854^{* *}$ & $-3.288^{* *}$ \\
& $(1.275)$ & $(1.438)$ \\
Profit & -2.965 & -1.159 \\
& $(2.562)$ & $(2.751)$ \\
ADInt & -9.418 & -9.659 \\
& $(6.738)$ & $(6.601)$ \\
Size & $0.196^{* *}$ & $0.234^{* *}$ \\
& $(0.094)$ & $(0.104)$ \\
C4 & $-0.013^{*}$ & -0.012 \\
& $(0.007)$ & $(0.007)$ \\
RDInt & & $-19.280^{*}$ \\
& & $(10.156)$ \\
Observations & 217 & 202 \\
Log-Likelihood & -84.43 & -78.14 \\
\hline
\end{tabular}

Notes: Standard errors in parentheses. Significant at the $1 \%\left({ }^{* * *}\right), 5 \%\left({ }^{* *}\right)$, and $10 \%\left({ }^{*}\right)$ level.

an indicator for a conspiracy having been detected and punished in the SIC industry during a ten year window around 1977. Profit is calculated as the ratio of operating income to sales (see Ravenscraft, 1983). ADInt is a proxy for product differentiation and is calculated as the ratio of advertising expense to revenue. Size proxies barriers to entry and is the natural logarithm of assets. $C_{4}$ is the industry's adjusted four-firm concentration ratio. ${ }^{10}$ Finally, RDInt is $\mathrm{R} \& \mathrm{D}$ intensity, calculated as the ratio of $\mathrm{R} \& \mathrm{D}$ costs to revenue. ${ }^{11}$ Please see Table 8 in Appendix I for more information on these variables.

cautions: "Special care is necessary when the specialization ratio or the coverage ratio is relatively low," the estimating sample for both specifications is restricted to only include industries with coverage and specialization ratios above the respective ratio's sample mean minus two standard errors.

${ }^{10}$ These were obtained for 1977 from Weiss and Pascoe's FTC Report (1986), "Adjusted Concentration Ratios in Manufacturing, 1972 and 1977."

${ }^{11}$ Unfortunately, this measure does not separate product from process innovation. It also does not include government-funded R\&D. 
Model (1) is similar to a specification in Asch and Seneca (1976)'s well-known empirical price-fixing study, and the estimates here are qualitatively the same. Model (2) adds RDInt to the specification. Its coefficient estimate is statistically significant and negative in sign. The addition of RDInt to the specification causes a statistically significant improvement in $\log$-likelihood $(L R=12.57, p<0.001)$.

Though the inverse relationship between Collusion and REDInt in Model (2) is predicted by the conjecture that product innovation affects price collusion, collinearity is a potential issue. ${ }^{12}$ Another possible problem is that the price conspiracy data suffer to an unknown degree from selection bias. Collusion may indicate not only collusion-prone industries, but that subset of collusion-prone industries which are also prosecution-prone. Also, SIC industries are not antitrust markets; they are generally much broader in scope than antitrust markets (Werden, 1988). ${ }^{13}$

Even ignoring possible econometric issues, the significant, negative coefficient estimate on RDInt in Model (2) reveals correlation between price collusion and R\&D intensity, not necessarily causation. The inverse relationship might stem from firms who are successfully colluding, reducing their innovation intensities. Such behavior has been empirically documented. Erickson (1976) reports that price conspiracies had a detrimental effect on cost innovation in gymnasium seating, rock salt, and structural steel.

With these issues in mind, laboratory experiments were designed to see if exogenous variation in the expected return from product innovation causes observed variance in price collusion. ${ }^{14}$

\footnotetext{
${ }^{12}$ Correlations among the regressors and variance inflation factors (VIFs) are all low. However, the condition number is high (39.2). See Appendix I for diagnostic details.

${ }^{13} \mathrm{An}$ example specific to this sample is a price conspiracy involving three gas meter manufacturers. The relevant SIC industry includes not only gas meters, but also odometers, parking meters, pedometers, production counters, speedometers, tachometers, taxi meters, and many other products.

${ }^{14}$ Unfortunately, firm-level data, as opposed to industry-level data, have their own issues. In particular, $R \& D$ expenditure data are generally only available for public firms. Moreover, such data is rarely available at the line of business level (where antitrust violations occur). For example, DuPont participated in a
} 


\section{Experimental Evidence}

These experiments were designed to incorporate "product innovation" into laboratory markets so as to permit exogenous variation in the expected return from product innovation across multiple treatments. If the data reveal differences in market prices across treatments, they support the conjecture that the expected return from product innovation affects price collusion.

As a robustness check, the experiments were conducted at two universities: a large, public research school and a small, private liberal arts school. Subject behavior in the experiments need not be identical across the two schools for the data to support the conjecture. What is important is that any treatment differences - if they exist - are robust across the two subject populations.

The laboratory research most related to these experiments involves product differentiation (see Brown-Kruse, et al., 1993; Brown-Kruse and Schenk, 2000; Collins and Sherstyuk, 2000; García-Gallego and Georgantzís, 2001; Barreda-Tarrazona, et al., 2011). In these cited papers, differentiation is captured by location choice. Here, innovation success or failure determines market size. Innovation is not rivalrous - one subject's innovation success is independent of another's. ${ }^{15}$ If successful, subjects enjoy one period of monopoly power; if unsuccessful, they must compete with other unsuccessful subjects in a BertrandEdgeworth market.

In this paper, successful innovation affords the innovator a perfectly appropriable market. When unsuccessful, appropriability is nil; subjects compete in a perfectly homogeneous market whose size varies from one to four firms. This stark design allows for exogenous

automotive refinishing paint price conspiracy in the early 1990s. While aggregate R\&D data are easily obtained for DuPont, disaggregated R\&D data are not readily available for DuPont's automotive paint LOB.

${ }^{15}$ This is not a design where firms cooperate on $R \& D$, and perhaps subsequently engage in price collusion. See Potters and Suetens (2013) for a survey of experimental work in this domain. 
variation in the ex ante expected return from innovation. The experiments reflect two types of markets: one in which firms frequently develop short-lived, perfectly differentiated new products and another in which firms rarely develop such killer products and so almost always compete to sell a homogeneous product.

\subsection{Experimental Design}

In these experiments, undergraduate students with no prior experience in similar experimental markets acted as firm managers. Prior to the start of the experiment, the subjects were randomly assigned into groups of four, and they remained in their group for 25 subsequent periods. Each period was subdivided into two stages: an Innovation stage and a Market stage. In Innovation stages, subjects made innovation expenditure decisions, and in Market stages they made pricing decisions. Table 2 lists the key experimental parameters.

At the beginning of the experiment, subjects were endowed $\$ 4.00$ (where the $\$$ sign denotes experimental dollars). In each Innovation stage, every subject was given the option of purchasing $a$ innovation attempts. Each attempt cost $\$ 0.10$. Subjects could purchase up to 20 attempts each period. Innovation was a Bernoulli process; innovation attempts resulted in innovation success according to the function $\theta(a)=1-(1-\rho)^{a}$. The probability that any one attempt was successful, $\rho$, was $5 \%, 15 \%$, or $25 \%$ as discussed below. Attempts were purchased prior to the realization of the innovation outcomes, so all $a$ attempts were paid for, regardless of whether they were necessary to achieve innovation success ex post.

If a subject was successful, they developed a "New product" that they could sell as a monopolist for one (the current) period. In other words, if a subject was successful in an Innovation stage, they posted a price in their own New product market during the subsequent Market stage. Subjects who attempted no innovation, or who were unsuccessful in their attempts, competed in a Bertrand-Edgeworth market with other unsuccessful sellers 
Figure 1:

Determination of Market Type and Size

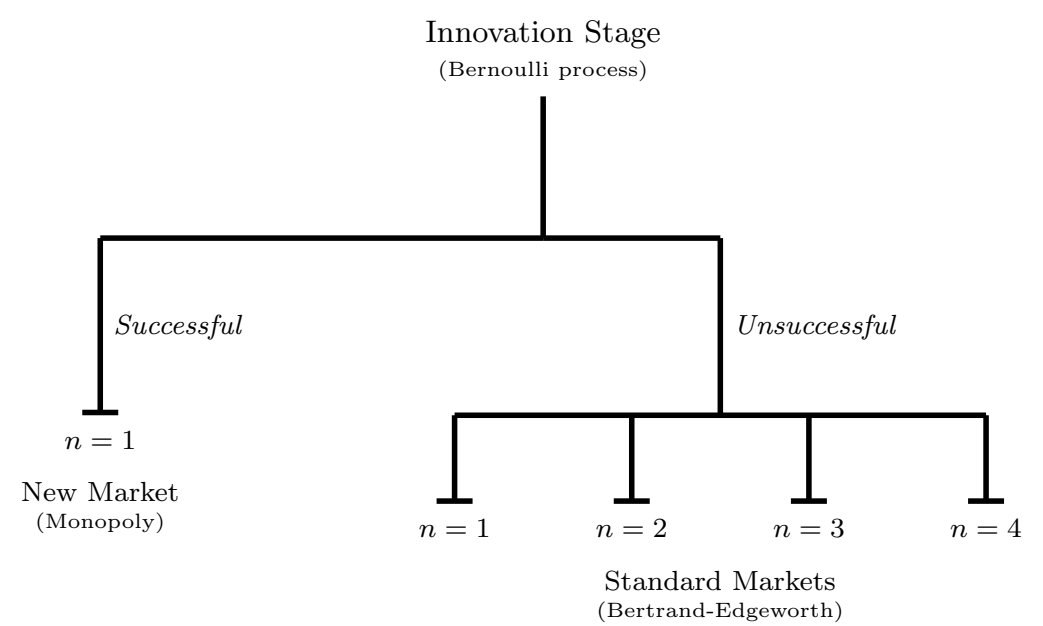

from their group, to sell a homogeneous "Standard product." As a function of the subjects' endogenous innovation expenditures and the stochastic innovation process, this Standard product market contained either $1,2,3$, or 4 sellers. If three of the four sellers in a group were successful, the lone unsuccessful subject in the Standard product market had their price automatically set to the lowest allowable price of $\$ 8.25$. This ensured that no unsuccessful innovator enjoyed monopoly power. Figure 1 shows how market type and size were determined.

The Market stage was timed. During the first five periods of the experiment, subjects had 60 seconds to submit a price. During the final twenty periods, they had 40 seconds. They were permitted to change their price as many times as they wished before time expired. A red timer counted down the remaining market time in a prominent location on each subject's computer screen.

For the entire experiment, the first three units a subject might sell cost $\$ 8.15$ experimental dollars to produce. The fourth unit they might sell cost $\$ 8.25$. Sellers were 
Table 2:

Experimental Parameters

\begin{tabular}{lc}
\hline Parameter & Value \\
\hline Endowment & $\$ 4.00$ \\
Attempts & {$[0,20]$} \\
Cost per attempt & $\$ 0.10$ \\
Prob(Innovation|1 Attempt) & $5 \%, 15 \%$, or $25 \%$ \\
Price & {$[\$ 8.25, \$ 20.00]$} \\
Unit production costs: & \\
$\quad q \leq 3$ & $\$ 8.15$ \\
$q=4$ & $\$ 8.25$ \\
$\quad q>4$ & $\infty$ \\
Market stage length: & \\
$\quad$ Periods 1-5 & 60 seconds \\
Periods 6-25 & 40 seconds \\
\hline
\end{tabular}

Notes: The $\$$ sign denotes experimental dollars.

capacity-constrained at 4 units. Units were "made to order," so production costs were only borne for units actually sold. Market demand and one seller's marginal costs are depicted in Figure 2.

The demand sides of the markets were automated. Each computerized buyer demanded a single unit at a unique reservation price. The queue was not random; buyers "queued up" in descending order of their reservation price $(\$ 10.01, \$ 9.76, \$ 9.51, \ldots)$. In New markets, the monopolist seller sold up to 4 units, depending on how many buyers had reservation prices above their posted price. In Standard markets, the seller posting the lowest price had the opportunity to make sales first. Buyers bought from a seller, conditional on that seller's price being less than their reservation price. If there was residual demand after the low-price seller made sales, the seller with the next lowest price could make sales. Thus, it was possible (and most often the case), that units of the homogeneous product sold for different prices in the same Standard market. When two or more sellers posted the same price, market demand was split evenly when possible. The experimental software randomly 
Figure 2:

Experimental Market Demand

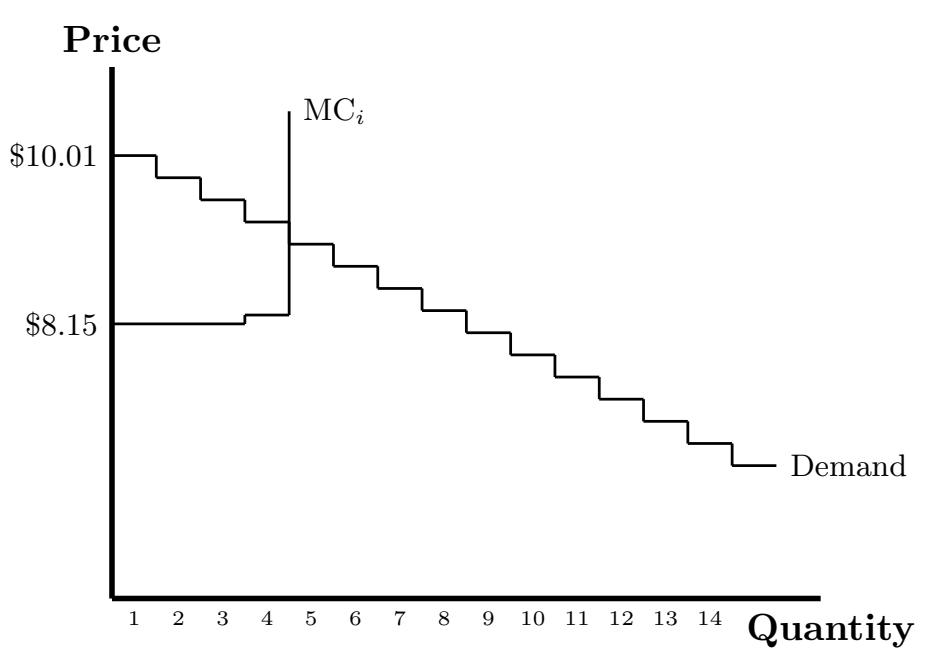

awarded the extra unit(s) in cases were demand could not be evenly split.

Because I am interested in differences in collusion across treatments and not collusion per se, the Market stage was constructed to lessen the coordination burden of collusion. It had the following features: (1) subjects could adjust their price as many times as they wished before market time expired, (2) their prices were publicly posted, (3) subjects were identified by numbers (i.e. Seller 1, ..., Seller 4) that were fixed throughout all 25 periods, (4) subjects could send unrestricted chat messages during Standard Market stages, and (5) subjects received feedback at the end of each period on the quantities sold by all members of their group. These features facilitated collusion in other experimental studies. ${ }^{16}$ They were present in all treatments.

There were two main treatments: a low innovation (LO) treatment where the chance of innovation success per attempt was $\rho=5 \%$, and a high innovation (HI) treatment where

\footnotetext{
${ }^{16}$ For example, Holt and Davis (1990) report that price announcements increase prices in posted-price markets (at least temporarily), Huck, Müller, and Normann (2001) show that fixed matching increases collusion, and Fonseca and Normann (2012) demonstrate that communication increases collusion in Bertrand oligopolies.
} 
Table 3:

Market Values

\begin{tabular}{lccc}
\hline Market type & Price & Quantity & Profit \\
\hline Standard $n=1$ & 8.25 & 4.00 & 0.30 \\
Standard $n=2$ & 8.25 & 4.00 & 0.30 \\
Standard $n=3$ & 8.25 & 2.67 & 0.27 \\
Standard $n=4$ & 8.25 & 2.00 & 0.20 \\
New $(n=1)$ & 9.26 & 4.00 & 4.34 \\
\hline
\end{tabular}

Notes: The Standard $n=1$ and $n=2$ values are not equilibrium values. See the text for explanation.

$\rho=15 \%$. A third, "super" high innovation (SHI) treatment with $\rho=25 \%$ is discussed later. Aside from the different $\rho$ 's, the treatments were exactly identical. Prior to the start of the experiment, subjects read instructions and had to successfully complete a short quiz on their content before preceding. Though the rationing rules for the two market types were explained to the subjects in detail, they were not told the specific reservation prices of the automated buyers. See Appendix III for the instructions.

\subsection{Price and Innovation Benchmarks}

In this section, I report price and innovation benchmarks for each treatment. Because innovation decisions were independent across periods, I construct innovation benchmarks for a single, representative period. I assume risk-neutral firms who innovate symmetrically. In other words, I assume that four firms independently select $a$ innovation attempts each period. To derive innovation benchmarks, I first determine or impose Market stage profits and then use these values to calculate innovation.

The Market stage prices, quantities, and profits used to calculate innovation benchmarks are shown in Table 3. Recall from Section 3.1 that price in the $n=1$ Standard market is set to $\$ 8.25$, which implies 4.00 units sold. A unique pure strategy Nash equi- 
librium of $\$ 8.25$ exists for the three- and four-seller Standard markets but there is no pure strategy price equilibrium for the two-seller market. In the three-seller Standard market, firms sell 2.67 units in expectation (eight units divided by three sellers), and in the fourseller Standard market each firm sells 2.00 units. For the two-seller case, I assume a price of $\$ 8.25$ and a quantity of 4.00 units. Finally, in the $n=1$ New market, profit-maximization implies 4.00 units sold at a price of $\$ 9.26$.

Importantly, the prices in Table 3 are the same across the LO, HI, and SHI treatments. It may appear unrealistic to assume that the price in the $n=2$ market will be the same as that in the $n=3$ or $n=4$ markets. For this reason, in addition to calculating benchmarks using the profits in Table 3, I calculate a second set of benchmarks using actual profit data from the experiments (this is described below).

Every period, there are sixteen $\left(2^{n}\right)$ possible innovation outcomes in the four firm market. Firm $i$ successfully innovates in eight of the outcomes and is unsuccessful and ends up in a Standard market in the other half of the outcomes. For the three firms that are not Firm $i$, let $\phi_{n}(a)=[\theta(a)]^{n-1}[1-\theta(a)]^{n}$ be the probability that $n \leq 3$ of these firms fail to successfully innovate when all firms independently make $a$ innovation attempts. So, for example, if 2 of the firms are unsuccessful $\phi_{2}(a)=\theta(a)[1-\theta(a)]^{2}$.

Among the eight cases where Firm $i$ is unsuccessful, there are three outcomes where two firms besides Firm $i$ are unsuccessful $\left(3 \phi_{2}\right)$ and three outcomes where one other firm besides Firm $i$ is unsuccessful $\left(3 \phi_{1}\right)$. There is also one outcome where all three firms besides Firm $i$ are unsuccessful $\left(\phi_{3}\right)$ and one outcome where Firm $i$ is the only unsuccessful firm $\left(\phi_{0}\right)$.

Thus, Firm $i$ maximizes:

$$
\Pi_{i}(a)=-c a+\theta(a) \pi_{N}+[1-\theta(a)]\left(\phi_{3}(a) \pi_{3}+3 \phi_{2}(a) \pi_{2}+3 \phi_{1}(a) \pi_{1}+\phi_{0}(a) \pi_{0}\right)
$$


Figure 3:

Expected Marginal Return and Cost of Innovation

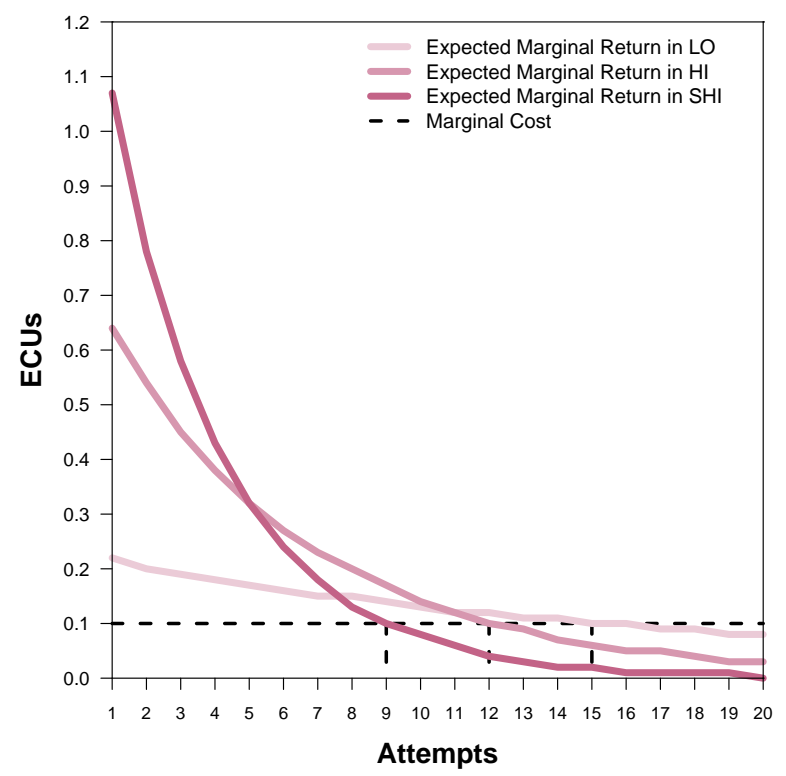

where $\pi_{N}$ is the New market profit and $\pi_{n}$ is the profit in the Standard market of size $n$. The coefficient $c$ is the cost per innovation attempt, which was $\$ 0.10$ in the experiments.

The innovation benchmarks that I report are the solutions to maximization problem (1) for each treatment; the $a \in[0,20]$ that maximize $\Pi_{i}(a)$. Equivalently, they are the number of attempts $\left(a^{*}\right)$ for which the expected marginal return from innovation equals the marginal cost of innovation. Figure 3 plots the expected marginal return from innovation for each treatment. This return varies across treatments because the probability of success per attempt parameter $(\rho)$ varies across treatments. Because the innovation success function in LO is less concave than the related functions in SHI and HI, the expected marginal return curve for LO in Figure 3 is flatter than the marginal return curves for SHI and HI.

Table 4 lists the innovation benchmarks and shows the likelihood that a firm ends 
Table 4:

Innovation Attempt Benchmarks

\begin{tabular}{lccc}
\hline & LO & HI & SHI \\
\hline Theoretical Profit & 15 & 12 & 9 \\
New Market Likelihood & 0.54 & 0.86 & 0.93 \\
\hline Actual Profit & 9 & 8 & 8 \\
New Market Likelihood & 0.37 & 0.73 & 0.90 \\
\hline
\end{tabular}

Notes: The Actual Profit benchmarks were generated using the observed average profits from each treatment (see Table 6). For HI-LA, the Actual

Profit innovation benchmark is 7 attempts (0.68).

up in the New market if they choose the benchmark number of attempts, that is, the probability $\theta\left(a^{*}\right)$. Because the prices in Table 4 may differ substantially from the prices actually observed in the experiments, I also calculate optimal innovation using the average prices in each treatment of the experiments. In other words, I use the prices in Table 6 for $\left(\pi_{N}, \pi_{1}, \pi_{2}, \pi_{3}, \pi_{4}\right)$. Table 4 suggests that LO subjects should attempt more innovation than HI or SHI subjects (see also Figure 3). When actual profits are used to generate the innovation benchmarks, they suggest that a similar amounts of innovation should be attempted in each treatment.

Because the experiments had known, finite time horizons, a Folk Theorem result with a supra-competitive price equilibrium in the Market stage is not strictly applicable. However, experiments have shown that subjects can be "irrationally" cooperative in noncooperative, finite horizon games. Huck, et al. (2004) remark: "In experimental praxis, an infinite number of periods is not required to make cooperation possible (often a few periods seem sufficient)." Thus, there is existing empirical evidence suggesting that supra-competitive ("cooperative") pricing may be possible in the Standard markets. This evidence suggests more cooperative pricing behavior in treatments where subjects have more Standard market 
experience.

There are two results from this section worth reiterating in summary: (1) For any market type, observed prices should be the same across treatments, and (2) LO subjects should attempt more innovation than $\mathrm{HI}$ or SHI subjects, but are likely to spend more time during the experiment in Standard markets than are $\mathrm{HI}$ or SHI subjects.

\subsection{Results}

The experiments were conducted at two universities; a large, public research school (R) and a small, private liberal arts school (LA). Subjects were recruited with ORSEE at the research school (Greiner, 2015) and by proprietary recruitment software at the liberal arts school. In both locations, the experiment was executed in z-Tree (Fischbacher, 2007).

Per the laboratory rules at the two schools, subjects received US $\$ 10.00$ at the research school and US $\$ 7.00$ at the liberal arts school for arriving at the computer lab on time. To equalize the average total payments across subject populations, the exchange rate between dollars and experimental currency was US $\$ 0.30$ for $\$ 1.00$ for the research school sessions and US $\$ 0.50$ for $\$ 1.00$ for the subjects at the liberal arts school. All treatments lasted approximately 1.5 hours, including roughly 15 minutes of computerized instructions. There were a total of 240 subjects; 48 in each treatment. Subjects had no previous experience in similar markets and no subject participated more than once.

\subsubsection{Did Innovation Vary Across Treatments?}

I first focus on the Innovation stage data from the LO and HI treatments and ask: Did attempted innovation vary across treatments, and if so, did subjects get differential experience in certain market types across treatments?

Figures $4 \mathrm{a}$ and $4 \mathrm{~b}$ show the average number of innovation attempts per market across 
Table 5:

Summary Statistics

\begin{tabular}{lrrrrr}
\hline & LO-R & HI-R & LO-LA & HI-LA & SHI-LA \\
\hline Subjects & 48 & 48 & 48 & 48 & 48 \\
Markets & 12 & 12 & 12 & 12 & 12 \\
Exchange rate (US\$ for \$) & $1 / 3$ & $1 / 3$ & $1 / 5$ & $1 / 5$ & $1 / 5$ \\
& & & & & \\
& $5 \%$ & $15 \%$ & $5 \%$ & $15 \%$ & $25 \%$ \\
Mean attempts per period & 2.42 & 4.43 & 1.67 & 2.45 & 2.99 \\
Time in New market & $10 \%$ & $46 \%$ & $7 \%$ & $27 \%$ & $52 \%$ \\
Time in Standard market & $90 \%$ & $54 \%$ & $93 \%$ & $73 \%$ & $48 \%$ \\
Modal market size & 4 & 1 & 4 & 1 & 1 \\
& & & & & \\
Chat messages & 787 & 201 & 977 & 599 & 392 \\
$\quad$ per market-period & 2.62 & 0.89 & 3.30 & 2.27 & 2.01 \\
& & & & & \\
Mean period earnings (US\$) & 0.20 & 0.49 & 0.36 & 0.60 & 0.97 \\
Mean total earnings (US\$) & 14.99 & 22.20 & 16.03 & 22.06 & 31.24 \\
\hline
\end{tabular}

Notes: The research school sessions include a US $\$ 10.00$ show-up fee and the liberal arts school sessions include a US\$7.00 show-up fee.

time. Clearly, on average, subjects in both treatments under-invested in innovation relative to the benchmarks from Section 3.2. ${ }^{17}$ Figure 3 suggests a possible explanation for this result: For a small number of attempts, the expected marginal return from an attempt is greater in HI than in LO. Subjects may have keyed on this fact, instead of on the actual optimality condition for innovation, that marginal return equal marginal cost.

Despite the benchmarks suggesting more innovation attempts in LO than HI, HI subjects attempted more innovation than LO subjects in both populations. The attempts graphs in Figure 4 and the average attempts per period figures in Table 5 indicate that the level of innovation attempted was not robust to changes in the subject population. For each treatment, the liberal arts school subjects attempted less innovation than the research school subjects. However, there was a robust treatment effect: In both populations,

\footnotetext{
${ }^{17}$ Under-investment is also observed in similar experimental environments in Isaac \& Reynolds (1992) and Smyth (2016).
} 
subjects attempted more innovation in HI than LO.

Because innovation success was an increasing function of the number of innovation attempts, and because more innovation was attempted in HI, there is a difference in the market size distribution between LO and HI. In other words, LO and HI subjects had differential experience in certain market types. Figures $4 \mathrm{c}$ and $4 \mathrm{~d}$ show the distribution of market-periods across market size (denoted by $n) .{ }^{18}$ In both figures, "New" refers to the New market, and $n=1$ refers to the $n=1$ Standard market.

The number of market-periods of experience increased monotonically with market size in both LO treatments (ignoring the $n=1$ Standard market type). By contrast, in the HI-R treatment, the number of market-periods decreased monotonically with market size (again, ignoring $n=1$ Standard markets). Table 5 shows that the modal market size was $n=4$ in LO, but was the New $(n=1)$ market in the HI treatment. Subjects were in Standard markets $90 \%$ and $93 \%$ of the time in LO-R and LO-LA, respectively, but were in a Standard market just $54 \%$ of the time in HI-R.

Thus, LO-R subjects ended up in Standard markets more frequently than HI-R subjects as predicted by the innovation benchmarks, even though all subjects under-invested relative to the benchmarks. Interestingly, while HI-LA subjects attempted more innovation than LO-LA subjects, they did not attempt nearly as much innovation as HI-R subjects. As a result, HI-LA subjects spent $73 \%$ of their time in a Standard market. Because relatively little innovation was attempted in HI-LA, an additional "super" high innovation (SHI) treatment was conducted with subjects from the liberal arts school population. The chance of innovation success per attempt was $\rho=25 \%$ for this treatment. This value of $\rho$ was chosen with the hope of replicating a distribution of market sizes closer to HI-R than

\footnotetext{
${ }^{18}$ The number of market-periods in any given period ranged from 1 (zero subjects successfully innovated) to 4 (all subjects successfully innovated). Thus, the number of market-periods is not identical to the number markets $\times$ periods. During one of the sessions, an error was detected in the software code. This glitch affected two market-periods in the LO-LA treatment. These market-periods are dropped from the analysis.
} 
Figure 4:

Innovation Attempts and Market Type and Size, by Treatment

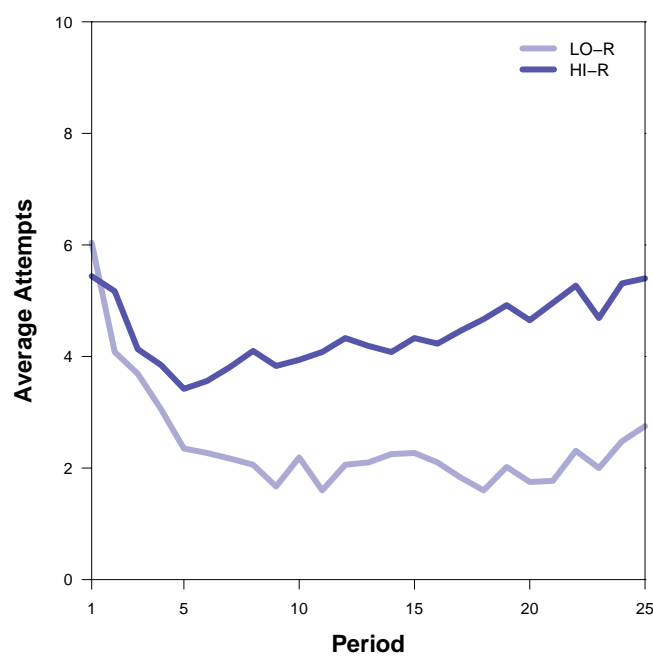

(a) Attempts on Time, $\mathrm{R}$

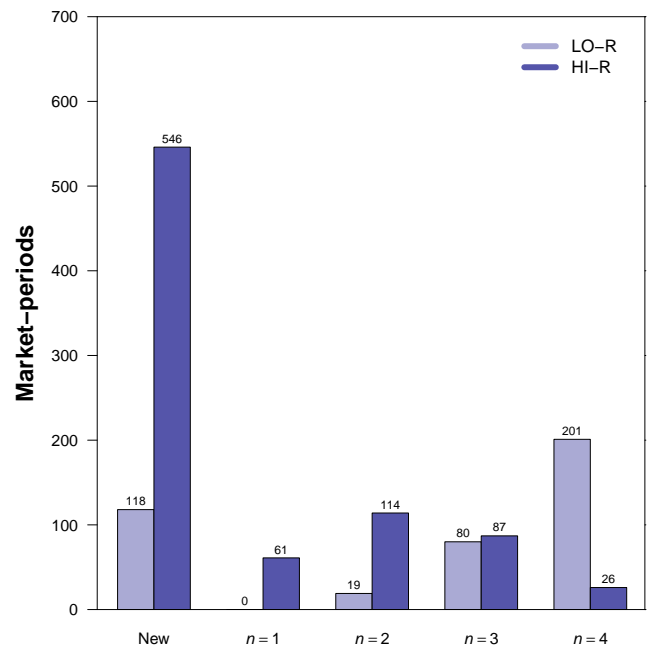

(c) Market Size Distribution, $\mathrm{R}$

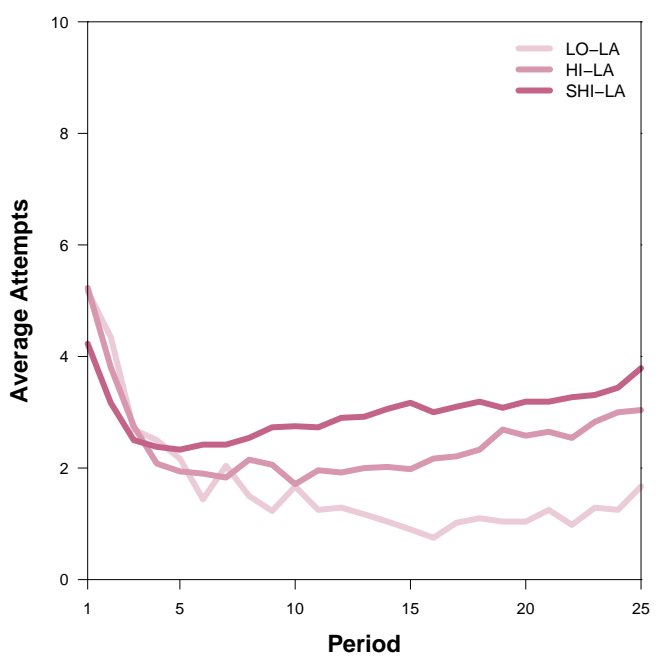

(b) Attempts on Time, LA

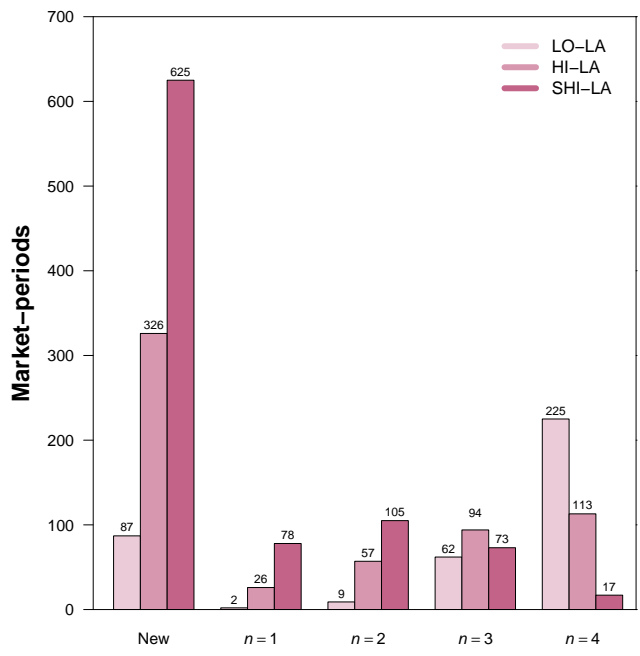

(d) Market Size Distribution, LA 


\section{HI-LA.}

To see the effect of increasing $\rho$ to $25 \%$ in the LA subject population, compare HI-R in Figure 4c to HI-LA and SHI-LA in Figure 4d. This comparison shows that the market size distribution in SHI-LA was much closer to that in HI-R than it was to the market size distribution in HI-LA. Having established that LO-R (LO-LA) subjects spent more time in Standard markets and less time in New markets than HI-R (SHI-LA) subjects, I now report Market stage data, beginning with summary statistics for Standard market communication.

\subsubsection{Did Subjects Attempt Collusion?}

Table 5 lists the average number of chat messages for each treatment. The figures are reported per market-period to account for the greater Standard market experience of LO subjects. The data suggest that subjects in low innovation treatments communicated more frequently than their higher innovation treatment counterparts. Across all Standard markets, LO-R subjects communicated nearly three times as often as HI-R subjects. They sent an average of 2.62 chat messages per market-period, compared to 0.89 messages per market-period in HI-R. In the liberal arts school sessions, LO-LA subjects sent over one and a half times as many messages per market period as SHI-LA subjects (3.30 to 2.01).

Did subjects discuss pricing? Note that they had no reason to not explicitly chat about prices. Several recent papers explore issues related to antitrust enforcement using experiments, but because of the complexity of the subjects' decision task in this paper, these experiments had no "antitrust enforcement." 19 Adding enforcement to this design ran the risk of overwhelming subjects, and as noted in Section 3.1, this paper focuses on collusion across treatments, not on the existence of collusion per se. Because subjects faced

\footnotetext{
${ }^{19}$ See Bigoni, et al. (2015) and the references therein, and Block and Gerety (1987).
} 
no threat of punishment for explicitly communicating about prices, messages from early periods included:

Period 2 of a LO-R market: "do you guys want to each sell at the same price?" Period 3 of a SHI-LA market: "lets all do above 8.25"

Period 4 of a HI-LA market: "Why don't we both sell at high prices?"

Period 3 of a LO-LA market: "lets try something like 915?"

Period 5 of a HI-R market: "dont do 8.25 then none of us profit silly"

Period 7 of a LO-R market: "can we all agree on $\$ 9$ ?"

Period 8 of a HI-R market: "how about we all put the same price"

Period 8 of a SHI-LA market: "we will all make more go high not low"

These examples are not cherry-picked. From the chat transcripts, it is clear that subjects in all treatments attempted explicit collusion early and often. As in previous collusion experiments with communication, subjects used the chat interface to further price manipulation. ${ }^{20}$ Please see Appendix II for a chat excerpt involving a rotation scheme in the LO-R treatment.

Subjects in all treatments attempted price collusion, but were subjects equally successful at price fixing? To answer this question, I turn to this paper's main empirical results that compare prices across the treatments.

\subsubsection{Did Prices Vary Across Treatments?}

In this section, I report price data from the experiments as averages and distributions. Table 6 contains average market prices. For market $m$ in period $t$, let the share-weighted market price be

$$
\bar{p}_{t}^{m}=\sum_{i=1}^{n_{m t}} s_{t}^{i} \cdot p_{t}^{i}
$$

where $n_{m t}$ denotes the number of sellers in market $m$ in period $t$, and $s_{t}^{i}$ and $p_{t}^{i}$ are Firm $i$ 's market share and price, respectively. The average market price is $\bar{p}_{t}^{m}$ averaged over all

\footnotetext{
${ }^{20}$ Full chat transcripts are available from the author.
} 
Table 6:

Average Market Price

\begin{tabular}{lccccccc}
\hline Market size & Theory & LO-R & HI-R & LO-LA & HI-LA & SHI-LA & Mean \\
\hline$n=1$ (New) & 9.26 & 9.34 & 9.30 & 9.15 & 9.28 & 9.24 & 9.26 \\
& & $(0.04)$ & $(0.01)$ & $(0.06)$ & $(0.02)$ & $(0.01)$ & $(0.03)$ \\
$n=2$ & n/a & 8.80 & 8.68 & 8.71 & 8.79 & 8.73 & 8.74 \\
& & $(0.14)$ & $(0.04)$ & $(0.13)$ & $(0.08)$ & $(0.05)$ & $(0.09)$ \\
$n=3$ & 8.25 & 8.58 & 8.58 & 8.85 & 8.66 & 8.57 & 8.65 \\
& & $(0.05)$ & $(0.04)$ & $(0.07)$ & $(0.05)$ & $(0.05)$ & $(0.05)$ \\
$n=4$ & 8.25 & 8.62 & 8.44 & 8.72 & 8.63 & 8.36 & 8.55 \\
& & $(0.03)$ & $(0.08)$ & $(0.03)$ & $(0.04)$ & $(0.05)$ & $(0.05)$ \\
\hline
\end{tabular}

Notes: Average market price is equation (2) averaged over all markets (in a treatment) and time. All prices in experimental dollars. Standard errors in parenthesis.

markets and periods.

Table 6 shows that average market prices decreased in market size. Note that the average New market price across all treatments was exactly the theoretical profit-maximizing price. For each Standard market type, average market prices were all well above $\$ 8.25$. In the $n=4$ markets, average market prices in the LO treatment were statistically higher than those in the HI and SHI treatments. A robust rank order test indicates that the mean of the distribution of average market prices for LO-R is greater than the corresponding mean for HI-R $(U=2.13, p=0.033$, two-tailed). The same is true for the equivalent LO-LA and SHI-LA comparison ( $U=4.76, p<0.001$, two-tailed).

Figure 5 shows the distribution of average market prices across treatments. It contains empirical cumulative distribution functions for the New market and the $n>1$ Standard markets. The horizontal axis in the figures is $\bar{p}_{t}^{m}$. I use Kruskal-Wallis tests to examine differences in Figure 5. In this context, the test asks whether prices from at least one of the treatments differ from prices in all of the treatments, when randomly paired (Kruskal and Wallis, 1952). Table 7 shows the results. 
Figure 5:

Empirical Cumulative Distribution Functions, by Market Type and Size

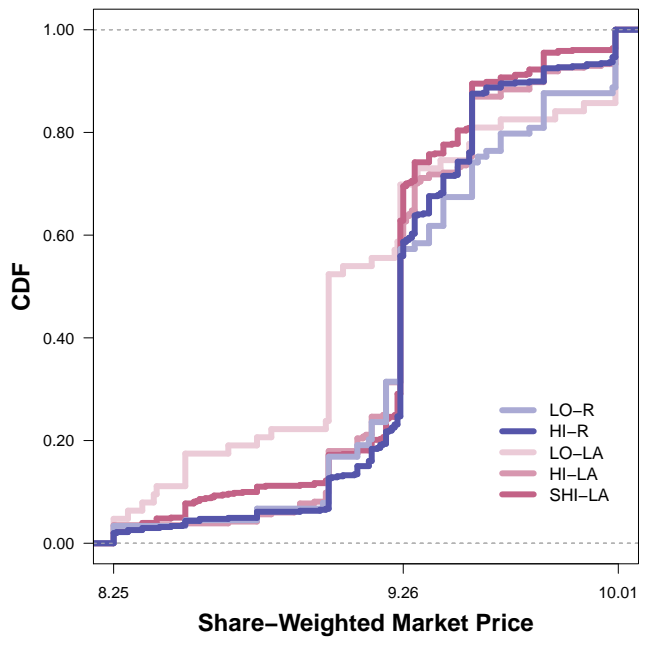

(a) New $(n=1)$ Market

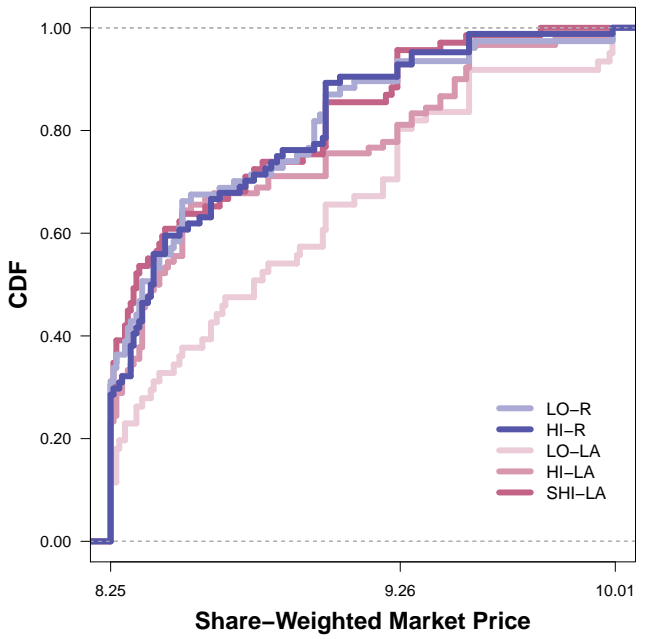

(c) Standard $n=3$ Market

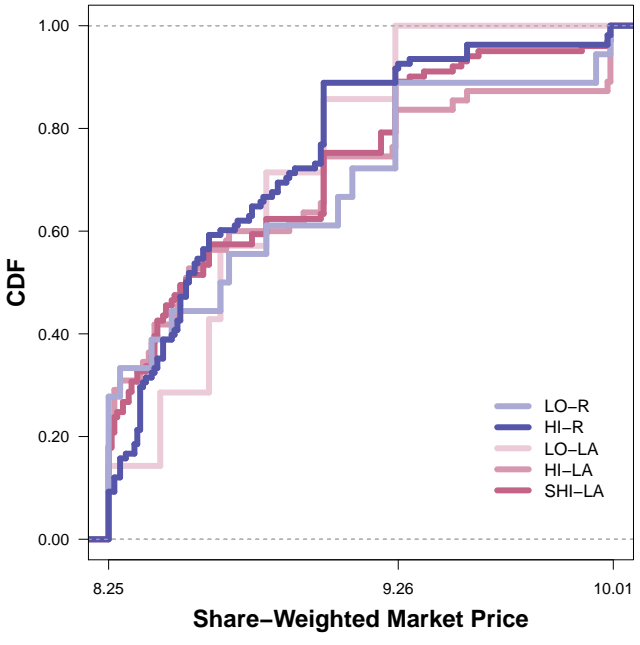

(b) Standard $n=2$ Market

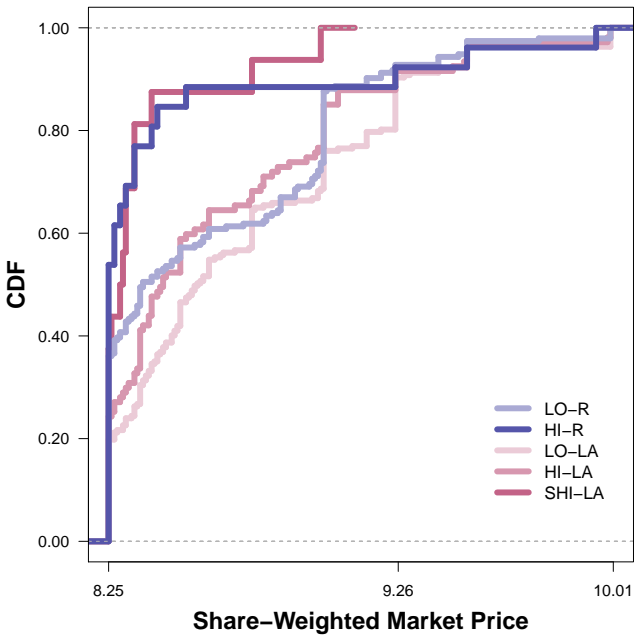

(d) Standard $n=4$ Market 
Table 7:

Kruskal-Wallis Test Results

\begin{tabular}{llrr}
\hline Market size & $d f$ & \multicolumn{1}{c}{$\chi^{2}$} & $p$-value \\
\hline$n=1$ (New) & 4 & 8.272 & 0.082 \\
$\quad$ excluding LO-LA & 3 & 4.205 & 0.240 \\
$n=2$ & 4 & 0.061 & 0.999 \\
$n=3$ & 4 & 2.314 & 0.678 \\
$n=4$ & 4 & 13.672 & 0.008 \\
$\quad$ excluding HI-R, SHI-LA & 2 & 0.641 & 0.726 \\
\hline
\end{tabular}

Notes: The tests were conducted on market averages over all periods because observations are not independent across periods.

The Kruskal-Wallis tests suggest that prices in at least one treatment in both the New and $n=4$ market sizes were different from those of their market size companions. From Figure 5a, it appears that LO-LA had lower prices in the New market size. Figure $5 \mathrm{~d}$ suggests that HI-R and SHI-LA had lower prices in the $n=4$ market size. When these treatments are excluded from additional Kruskal-Wallis tests, there is no statistically significant difference between the remaining treatments.

This section reports significant differences in $n=4$ Standard market prices between the LO and higher innovation treatments. The next section addresses the relationship between market experience and market price.

\subsubsection{Does Experience Explain The Price Variance?}

In light of the price data, note again the disparity in the number of $n=4$ market-periods across the low and higher innovation treatments in Figure 4. Did LO subjects' greater experience in the $n=4$ markets affect prices?

Figure 6 graphs market price on market experience for the largest Standard market size. Specifically, it shows the average of $\bar{p}_{t}^{m}$ over $t$ on the number of $n=4$ market-periods 
Figure 6:

Market Price on $n=4$ Market Experience

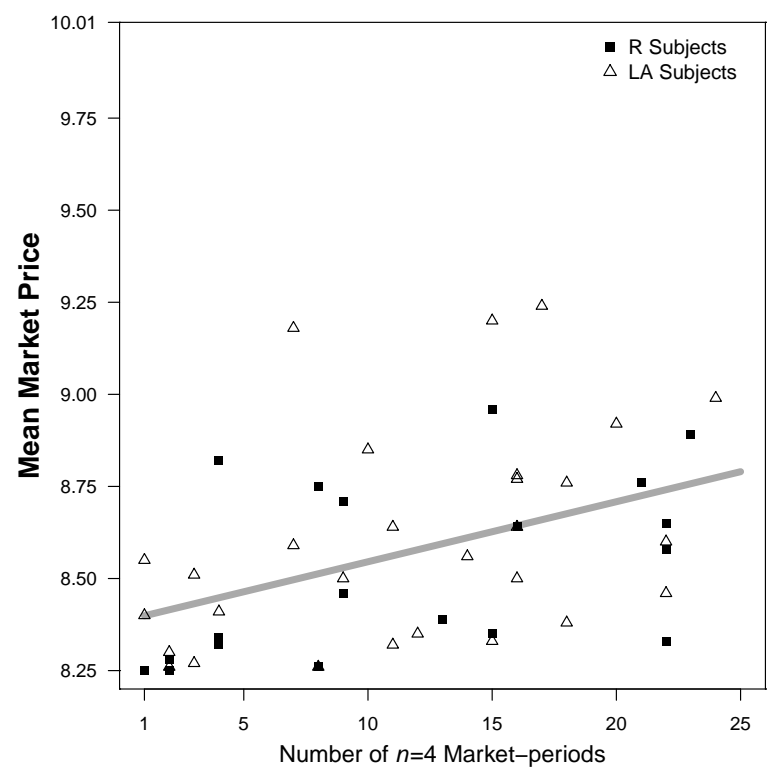

for market $m$. The line in the figure was generated by the ordinary least squares regression

$$
\frac{1}{T} \sum_{t=1}^{T} \bar{p}_{t}^{m}=\underset{(0.056)}{8.382}+\underset{(0.004)}{0.016} \cdot \text { Experience }^{m}
$$

where Experience $^{m}$ is the total number of periods that market $m$ was in a $n=4$ market. $^{21}$ Across all treatments, market experience had a significant, positive effect on market price in $n=4$ markets.

While it is conceivable that experience was endogenous to price in the above regression, this is unlikely in principle. Even if all firms post the joint monopoly price of $\$ 9.26$ in an $n=4$ market, they only receive one quarter of the profit they would receive in a New

\footnotetext{
${ }^{21}$ Standard errors in parenthesis. The coefficient estimate on experience is still statistically, significantly different from zero $(p<.001)$ when an indicator variable for subject population is added to specification (3). The coefficient estimate for this indicator is not significantly different from zero $(p=0.297)$.
} 
Figure 7:

Estimates of $\beta_{i, 1}$ in Model (4)

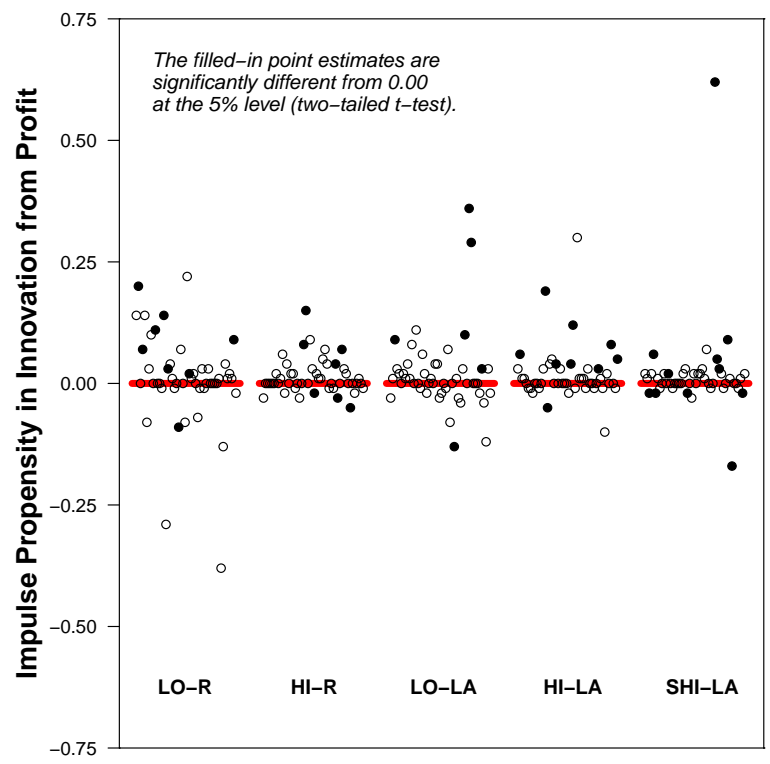

market. ${ }^{22}$ So it seems unlikely that firms would reduce their innovation expenditure (which affects experience) because of the market price. Still, I now examine individual innovation decisions to see if past collusive success affected future innovation decisions.

\subsubsection{Did Collusive Success Affect Innovation?}

The preceding results suggest that the exogenously-determined expected return from innovation affected market outcomes. It is also possible that market outcomes, in turn, endogenously affected innovation decisions. For example, subjects who successfully coordinated to raise market price may have subsequently curtailed their innovative activity.

To investigate the relationship between collusive success and subjects' innovation ex-

\footnotetext{
${ }^{22}$ This calculus does ignore the costs savings from foregoing all innovation attempts.
} 
penditures, a distributed lag model was estimated for each subject

$$
\text { Innovation }_{i, t}=\beta_{i, 0}+\sum_{k=1}^{5} \beta_{i, k} \cdot \text { Profit }_{i, t-k}+\epsilon_{i, t}
$$

where Innovation $_{i, t}$ is subject $i$ 's innovation expenditure and Profit ${ }_{i, t-k}$ is market profit (gross of innovation expenditures) in period $t-k$. The coefficient estimate $\hat{\beta}_{i, 1}$ is the impulse propensity in innovation expenditure from changes in market profit during period $t-1$. If a subject successfully coordinated with other subjects to raise the Standard market price, and then reduced his or her innovation expenditure in order to profit maximize, $\hat{\beta}_{i, 1}<0$. In other words, if innovation expenditure is endogenous to collusive success, the impulse propensity is negative.

Specification (4) was estimated for all 240 subjects with standard errors adjusted for heteroskedasticity. Because of the five lags, each estimating sample had 20 observations. Figure 7 shows $\hat{\beta}_{i, 1}$ for each subject, organized by treatment. Estimates that are significantly different from zero at the five percent level (two-tailed t-test) are filled-in.

Only $3 \%$ of the subjects ( 7 of 240 ) had zero variance in their innovation expenditure, yet $83 \%$ (199 of 240 ) of the estimates of $\beta_{i, 1}$ are not significantly different from zero. ${ }^{23}$ To the extent that serial correlation is present in the data, even the significant estimates in Figure 7 may be chimeric, as serial correlation lowers standard errors. Furthermore, 73\% (30 of 41) of the significant estimates are positive, indicating that - if anything, innovation expenditure increased in last period's profit. Finally, the economic magnitude of the estimates is trivial: They suggest that, on average, a $\$ 1.00$ increase in market profit resulted in a $\$ 0.02$ increase in innovation expenditure.

\footnotetext{
${ }^{23}$ Similar results are obtained for tests of the null hypothesis that the coefficients on all five lags sum to zero, or that the coefficients on all five lags are jointly equal to zero.
} 


\subsection{Discussion}

"If [the firm] is in business permanently, the temporary gains of a price cut are of negligible importance... On the other hand, if [the firm] is in the market only temporarily, bent on disposing of a certain amount of product, the ultimate consequences do not enter into [its] calculations." — Chamberlin [1962]

The experimental results can be summarized as follows: The exogenously-greater expected return from innovation in $\mathrm{HI}$ and $\mathrm{SHI}$ induced more innovation expenditure in those markets relative to the LO markets. This difference translated into more $n=4$ market experience for LO subjects relative to HI-R and SHI-LA subjects. Market experience then affected the success of price collusion in the manner suggested by Chamberlin's epigraph. HI and SHI subjects could afford to price snipe in the $n=4$ markets, whereas LO subjects could not.

In the experiments, it was as though HI-R and SHI-LA subjects inhabited a world of killer products. These subjects were in Standard markets far less frequently than their LO counterparts. They rarely ended up in $n=4$ markets and often enjoyed monopoly-like profit in New markets. The data suggest that when they were in Standard markets, the long term benefits of abstaining from price sniping did not resonate with HI-R and SHI-LA subjects.

The situation was different in LO markets. One LO subject lamented, "the innovative stage is a visual representation of [hopes] and dreams being crushed," and another bemoaned, "I wonder what the new market is even like." The LO treatment was like a market devoid of killer products. Meager profits and the prospect of similar future earnings impressed upon LO subjects the necessity of cooperation. Because innovation was infrequent in LO, it was not as disruptive to coordination as in HI-R or SHI-LA.

Importantly, the data provide scant evidence that collusive success affected innovation decisions. Rather, they indicate that successful Market stage collusion did not feed back 
and affect Innovation stage expenditure. The observed difference in innovation across treatments stemmed from the exogenous difference in the expected return from innovation and not from any endogenous changes in subject innovation expenditure due to market outcomes.

\section{Conclusion}

This paper tests the conjecture that the expected return from product innovation affects price collusion with archival and experimental data. Regression analysis of archival data is consistent with the idea that price collusion is more likely where the expected return from innovation is lower. However, this analysis is unsatisfying for several reasons, including its inability to discern causation.

To examine the causal relationship between product innovation and price collusion in a controlled way, experiments were conducted where the only exogenous treatment variation was the ex ante expected return from innovation. Subjects in all treatments explicitly discussed supra-competitive pricing, but average market prices in a low innovation treatment were significantly greater than those in higher innovation treatments. The data illustrate how low expected returns from product innovation may aid collusion, while higher expected returns from such innovation may frustrate it.

If the expected return from product innovation affects price collusion, this helps explain why price collusion appears endemic in many markets. Firms that cannot escape competition through product innovation may turn to conspiracy as an alternative avenue to supra-competitive profit. Because these firms cannot innovate their way to higher profit, they return time and again to price manipulation. Instead of merry trade meetings turning to conspiracy, in markets with low expected returns from product innovation, the scene may be better set by Shakespeare than Smith: "O mischief, thou art swift to enter in the 
thoughts of desperate men!" 


\section{References}

Asch, Peter, and Joseph Seneca. "Characteristics of collusive firms." The Journal of Industrial Economics 23, no. 3 (1975): 223-37.

Asch, Peter, and Joseph Seneca. "Is collusion profitable?" The Review of Economics and Statistics (1976): 1-12.

Barreda-Tarrazona, Ivan, Aurora García-Gallego, Nikolaos Georgantzís, Joaquin Andaluz-Funcia, and Agustin Gil-Sanz. "An experiment on spatial competition with endogenous pricing." International Journal of Industrial Organization 29, no. 1 (2011): 74-83.

Bigoni, Maria, Sven-Olof Fridolfsson, Chloé Le Coq, and Giancarlo Spagnolo. "Trust, leniency, and deterrence." Journal of Law, Economics, and Organization 31, no. 4 (2015): 663-689.

Block, Michael, and Vernon Gerety. "Deterring collusion: Some experimental evidence on the relative effectiveness of changes in detection and sanction levels." Unpublished Manuscript (1987).

Brown-Kruse, Jamie, Mark Cronshaw, and David Schenk. "Theory and experiments on spatial competition." Economic Inquiry 31, no. 1 (1993): 139-65.

Brown-Kruse, Jamie, and David Schenk. "Location, cooperation and communication: An experimental examination." International Journal of Industrial Organization 18, no. 1 (2000): $59-80$.

Chamberlin, Edward. The Theory of Monopolistic Competition. Cambridge, MA: Harvard University Press, 1962.

Collins, Richard, and Katerina Sherstyuk. "Spatial competition with three firms: an experimental study." Economic Inquiry 38, no. 1 (2000): 73-94.

Colombo, Stefano. "Product differentiation and collusion sustainability when collusion is costly." Marketing Science 32, no. 4 (2013): 669-674.

Dick, Andrew. "Identifying contracts, combinations and conspiracies in restraint of trade." Managerial and Decision Economics 17, no. 2 (1996): 203-216.

Erickson, Bruce. "Price fixing conspiracies: Their long-term impact." The Journal of Industrial Economics (1976): 189-202.

Evans, David, and Richard Schmalensee. "Some economic aspects of antitrust analysis in dynamically competitive industries." In Innovation Policy and the Economy, Volume 2, 1-50. Cambridge, MA: MIT Press, 2002.

Fischbacher, Urs. "z-Tree: Zurich toolbox for ready-made economic experiments." Experimental Economics 10, no. 2 (2007): 171-178.

Fonseca, Miguel, and Hans-Theo Normann. "Explicit vs. tacit collusion-the impact of communication in oligopoly experiments." European Economic Review 56, no. 8 (2012): 1759-1772.

Fraas, Arthur, and Douglas Greer. "Market structure and price collusion: An empirical analysis." The Journal of Industrial Economics (1977): 21-44. 
García-Gallego, Aurora, and Nikolaos Georgantzís. "Multiproduct activity in an experimental differentiated oligopoly." International Journal of Industrial Organization 19, no. 3 (2001): 493-518.

Greiner, Ben. "Subject pool recruitment procedures: Organizing experiments with ORSEE." Journal of the Economic Science Association 1, no. 1 (2015): 114-125.

Häckner, Jonas. "Collusive pricing in markets for vertically differentiated products." International Journal of Industrial Organization 12, no. 2 (1994): 155-177.

Hay, George, and Daniel Kelley. "An empirical survey of price fixing conspiracies." Journal of Law Es Economics 17 (1974): 13.

Holt, Charles, and Douglas Davis. "The effects of non-binding price announcements on posted-offer markets." Economics Letters 34, no. 4 (1990): 307-310.

Huck, Steffen, Wieland Müller, and Hans-Theo Normann. "Stackelberg beats Cournot-on collusion and efficiency in experimental markets." The Economic Journal 111, no. 474 (2001): 749-765.

Huck, Steffen, Hans-Theo Normann, and Jorg Oechssler. "Two are few and four are many: number effects in experimental oligopolies." Journal of Economic Behavior \&3 Organization 53, no. 4 (2004): 435-446.

Isaac, Mark, and Stanley Reynolds. "Schumpeterian competition in experimental markets." Journal of Economic Behavior 83 Organization 17, no. 1 (1992): 59-100.

Kruskal, William, and Allen Wallis. "Use of ranks in one-criterion variance analysis." Journal of the American Statistical Association 47, no. 260 (1952): 583-621.

Levenstein, Margaret, and Valerie Suslow. "What determines cartel success?" Journal of Economic Literature 44, no. 1 (2006): 43-95.

Potters, Jan, and Sigrid Suetens. "Oligopoly experiments in the current millennium." Journal of Economic Surveys 27, no. 3 (2013): 439-460.

Ravenscraft, David, and Curtis Wagner. "The role of the FTC's line of business data in testing and expanding the theory of the firm." Journal of Law 83 Economics 34 (1991): 703.

Ravenscraft, David. "Structure-profit relationship at the line of business and industry level." The Review of Economics and Statistics (1983): 22-31.

Scherer, Frederic, William Long, Stephen Martin, Dennis Mueller, George Pascoe, David Ravenschaft, John Scott, and Leonard Weiss. "The validity of studies with line of business data: comment." The American Economic Review (1987): 205-217.

Scherer, Frederic, and David Ross. Industrial Market Structure and Market Performance: Third Edition. Boston: Houghton Mifflin, 1990.

Smyth, Andrew. "Competition, cost innovation, and x-inefficiency in experimental markets." Review of Industrial Organization 48, no. 3 (2016): 307-331.

Sonnenfeld, Jeffrey, and Paul Lawrence. "Why do companies succumb to price fixing?" Harvard Business Review 56, no. 4 (1978): 145-157. 
Sutton, John. Technology and Market Structure: Theory and History. Cambridge, MA: The MIT Press, 1998.

Symeonidis, George. "Cartel stability in advertising-intensive and R\&D-intensive industries." Economics Letters 62, no. 1 (1999): 121-129.

Symeonidis, George. "In which industries is collusion more likely? evidence from the UK." The Journal of Industrial Economics 51, no. 1 (2003): 45-74.

Thomadsen, Raphael, and Ki-Eun Rhee. "Costly collusion in differentiated industries." Marketing Science 26, no. 5 (2007): 660-665.

Wallace, Donald. Market Control in the Aluminum Industry. Cambridge, MA: Harvard University Press, 1937.

Weiss, Leonard, and George Pascoe. "Adjusted concentration ratios in manufacturing, 1972 and 1977." United States Federal Trade Commission, 1986.

Werden, Gregory. "The divergence of SIC industries from antitrust markets: some evidence from price fixing cases." Economics Letters 28, (1988): 193-197. 


\section{Appendix I}

Table 8:

Archival Data Summary

\begin{tabular}{lllc}
\hline Variable & Source & Year(s) & Definition \\
\hline Collusion & CCH Trade Cases & $1972-1982$ & see text \\
Profit & LOB Report & 1977 & $\frac{\text { operating income }}{\text { total sales and transfers }}$ \\
ADInt & LOB Report & 1977 & $\frac{\log (\text { total adssets) }}{\text { revenues from outsiders }}$ \\
Size & LOB Report & 1977 & matched to LOB data by SIC code \\
C4 & Weiss and Pascoe [1986] & 1977 & $\frac{\text { cost of company R\&D }}{\text { revenues from outsiders }}$ \\
RDInt & LOB Report & 1977 &
\end{tabular}

Table 9:

Collinearity Diagnostics

\begin{tabular}{lrrrrrrr}
\hline & Collusion & Profit & ADInt & Size & C4 & RDInt & VIF \\
\hline Collusion & 1.00 & & & & & & \\
Profit & -0.11 & 1.00 & & & & & 1.14 \\
ADInt & -0.11 & 0.18 & 1.00 & & & & 1.06 \\
Size & 0.11 & 0.01 & 0.00 & 1.00 & & & 1.13 \\
C4 & -0.14 & 0.29 & 0.14 & 0.23 & 1.00 & & 1.18 \\
RDInt & -0.13 & 0.16 & -0.06 & 0.28 & 0.21 & 1.00 & 1.15 \\
\hline
\end{tabular}

Condition Number (no centering): 39.19 
Table 10:

Collusion Sample

\begin{tabular}{|c|c|c|c|}
\hline Citation & SIC Code & Industry & R\&D Intensity \\
\hline 61,368 & 3273 & Ready-mix concrete & $\mathrm{n} / \mathrm{a}$ \\
\hline 62,519 & 3273 & Ready-mix concrete & $\mathrm{n} / \mathrm{a}$ \\
\hline 63,658 & 3273 & Ready-mix concrete & $\mathrm{n} / \mathrm{a}$ \\
\hline 63,659 & 3273 & Ready-mix concrete & $\mathrm{n} / \mathrm{a}$ \\
\hline 75,060 & 3271 & Concrete blocks & 0.000 \\
\hline 63,424 & 3272 & Precast concrete products & 0.000 \\
\hline 63,091 & 2026 & Dairy products & 0.001 \\
\hline 63,198 & 2026 & Dairy products & 0.001 \\
\hline 63,370 & 2026 & Dairy products & 0.001 \\
\hline 64,503 & 2026 & Dairy products & 0.001 \\
\hline 64,555 & 2026 & Fluid Milk & 0.001 \\
\hline 63,180 & 2011 & Meat packing & 0.001 \\
\hline 62,235 & 2062 & Refined sugar & 0.001 \\
\hline 74,657 & 3442 & Garage doors & 0.002 \\
\hline 75,197 & 2051 & Bread & 0.002 \\
\hline 61,664 & 2051 & Bread products & 0.002 \\
\hline 62,215 & 2051 & Bakery products & 0.002 \\
\hline 62,217 & 2051 & Bakery products & 0.002 \\
\hline 65,724 & 2051 & Pastries & 0.002 \\
\hline 63,586 & 2951 & Asphalt and concrete sales & 0.002 \\
\hline 62,916 & 3353 & Aluminum roll jacketing & 0.003 \\
\hline 62,702 & 3449 & Reinforcing steel bars & 0.003 \\
\hline 64,823 & 2076 & Coconut oil & 0.003 \\
\hline 74,929 & 2077 & Rendering & 0.003 \\
\hline 63,090 & 3449 & Reinforcing steel bars & 0.003 \\
\hline 63,475 & 3356 & Titanium mill products & 0.004 \\
\hline 62,992 & 2657 & Folding cartons & 0.005 \\
\hline 61,739 & 2499 & Toilet seats & 0.005 \\
\hline 64,222 & 3452 & Standard screws & 0.006 \\
\hline 63,000 & 3496 & Swine confinement systems & 0.006 \\
\hline 63,181 & 2673 & Consumer bags & 0.007 \\
\hline 75,245 & 2096 & Snack foods & 0.007 \\
\hline 63,643 & 2041 & Blended foods & 0.007 \\
\hline 63,227 & 2048 & Livestock feed & 0.008 \\
\hline 62,517 & 3494 & Furnace pipe and fittings & 0.010 \\
\hline 63,092 & 3643 & Wiring devices & 0.013 \\
\hline 74,945 & 2298 & Nylon twine & 0.013 \\
\hline 60,615 & 2672 & Paper labels & 0.015 \\
\hline 63,205 & 2672 & Pressure sensitive tape & 0.015 \\
\hline 60,785 & 3965 & Zipper sliders & 0.016 \\
\hline 63,609 & 3639 & Water heaters & 0.016 \\
\hline 60,846 & 3089 & Drainage, waste or vent plastic pipe fittings & 0.017 \\
\hline 63,215 & 3613 & Fuse products & 0.018 \\
\hline 61,447 & 2865 & Dyes & 0.020 \\
\hline 63,844 & 2869 & Dimethyl sulfoxide & 0.020 \\
\hline 63,784 & 3541 & Metal-working machinery & 0.024 \\
\hline 65,742 & 3952 & Art materials & 0.024 \\
\hline 62,901 & 2821 & Persulfate & 0.025 \\
\hline 63,610 & 2821 & Coatings resins & 0.025 \\
\hline 63,622 & 3824 & Gas meters & 0.043 \\
\hline
\end{tabular}

Notes: Horizontal price collusion in manufacturing industries, 1972-1982. Citations from Commerce Clearing House Trade Cases books. R\&D intensity calculated from LOB data. 


\section{Appendix II}

The following chat excerpt and Figure 8 illustrate a collusive episode in one of the LO-R markets. Discussion of a rotation scheme begins in Period 13 and the sellers first successfully implement it in Period 15. In the scheme, Sellers 1 and 3 (Sellers 2 and 4) post a "high" price - usually 10.00 - in odd (even) periods. The groups take turns posting a "low"

price. Initially, in Period 15, the "low" price is 8.85. By the time the scheme breaks down in Period 22, the collusive price has risen to 9.25. The rotation ends in Period 22 when Seller 4 cheats by posting a "low" price of 9.00 out of turn.

\section{Period 13}

Seller 1: "one person do 8 85"

Seller 1: "the rest 10"

...

Seller 1: "and we do that for the next 4 rounds"

Seller 1: "for everyone"

Seller 4: "every bofdy do 10 excpept 1, we can go in order"

Seller 4: "next time do three, then four, then back to 1 "

Period 14

..

Seller 3: "who is doing 8.85 in this one?"

Seller 1: "ok lets do it now"

..

Seller 4: "seller two put 8.85 "

Seller 4: "or not"

Period 15

Seller 3: "seller 2"

Seller 3: "do 8.85"

Seller 4: "guys, 1 person can only sell 4 products so two people have to be lower"

...

Seller 4: "so we can take turns by twos"

Seller 1: "good idea!"

Period 16

Seller 4: "1 and 3 does 8.85 now"

Seller 3: "so me and seller 1 go this time?"

Seller 1: "so 1 and 3 at 8.85?"

Seller 4: "perfect!"

...

Period 24

Seller 3: "seller 4 turned frank underwood on all of us" 24

\footnotetext{
${ }^{24}$ Frank Underwood is the main character (a duplicitous politician) of House of Cards, a popular television show when these experiments were run.
} 


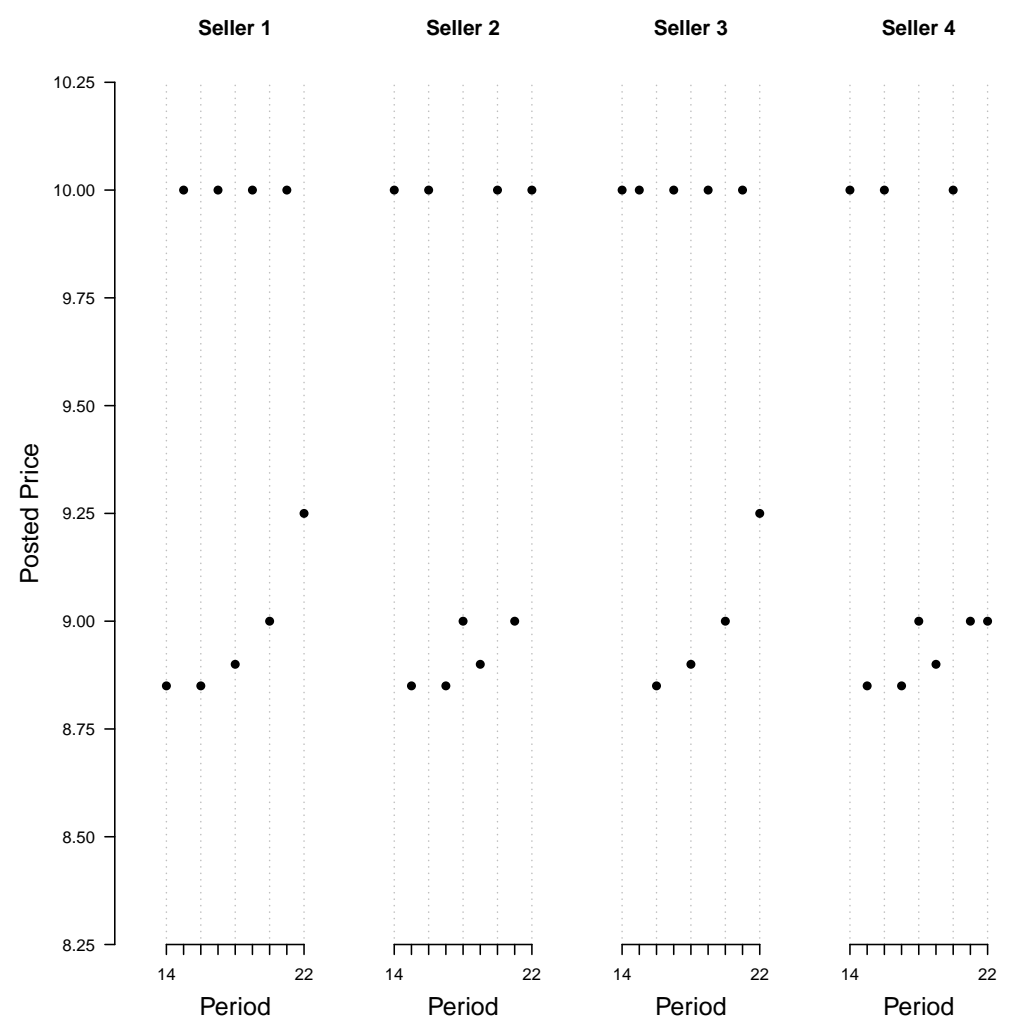

Figure 8:

An Example Collusive Episode 


\title{
Appendix III
}

This appendix gives the full instructions as they appeared to subjects in the LO [HI] treatment at the research school.

\author{
Instructions
}

This is an experiment on economic decision making.

Please turn off and stow all electronic devices (cell phones, computers, tablets, etc.).

If you have a question at any point during these instructions or during the experiment, please raise your hand and an experimenter will come to your terminal to address your question privately.

For participating in today's experiment you will receive a show-up fee of $\$ 10.00$ plus the amount you earn during the course of the experiment. During the experiment, your earnings (excluding show-up fee) will be designated in experimental dollars $(\$)$. At the conclusion of the experiment, experimental dollars will be converted into U.S. dollars (US\$) at an exchange rate of $\$ 10.00$ to US $\$ 3.00$.

You cannot leave today with less than your US\$10.00 show-up fee.

$\underline{\text { Timeline }}$

This experiment is composed of 25 periods.

Each period is divided into 2 stages.

In each period, you will first participate in an Innovation stage and then in a Market stage.

$\underline{\text { Market Stage }}$

In each Market stage of this experiment you will either sell units in the Standard product market or in a New product market. The difference between these two market types is discussed in detail below. The following instructions apply to both market types.

In each Market stage, you will have the opportunity to sell units of a good.

You can sell at most 4 units.

There are production costs for units you sell. Your production cost for the first three units you may sell is $\$ 8.15$ per unit. Your production cost for the fourth unit you may sell is $\$ 8.25$.

Examples:

Say you sell 1 unit. Your total production costs are: $1 \times 8.15=8.15$
Say you sell 2 units. Your total production costs are: $2 \times 8.15=16.30$
Say you sell 3 units. Your total production costs are: $3 \times 8.15=24.45$
Say you sell 4 units. Your total production costs are: $3 \times 8.15+1 \times 8.25=32.70$

In each Market stage you will submit a price. This is the price that you are willing to sell all of your units for. You cannot sell different units for different prices. Prices can be any two decimal number from $\$ 8.25$ to $\$ 20.00$.

In the first 5 Periods, the Market stage will last 60 seconds. For the remaining 20 periods, it will last 40 seconds. A timer on your computer screen will count down the 60 (40) seconds. You may adjust your price (either up or down) as many times as you wish during the 60 (40) seconds. The prices you submit will be displayed in the box labeled 'Prices' in the upper right corner of your computer screen. Once the 60 (40) seconds have run out, your price is "locked in." Thus, the last price you submit before time expires is the price that counts. If you wish to make absolutely certain that the computer registers your final price, do not wait until the final few seconds of the stage to submit your last price. 
You will be in a market with as many as three other sellers. These other sellers are currently reading the same instructions you are and will be confronting the same decisions that you will. You may send messages to the other sellers in your market using the box labeled 'Chat' in the lower left corner of your computer screen. Do not use profanity or make threats while chatting!

The buyers in this experiment are computerized. Each buyer has some $\$$ value for 1 unit. We refer to this value as their buyer value.

If you are in a New product market, you produce a unique product and will not have to compete with other sellers to sell units. The number of units that you sell will depend on the price that you submit. Buyers will buy a unit from you if your price is less than or equal to their buyer value.

If you are in a Standard product market, you will compete with other sellers to sell units to buyers who will buy a unit from you if your price is less than or equal to their buyer value.

If you submit a price that is lower than the prices submitted by all the other sellers in your market, buyers will "line up" to purchase from you first.

If you submit a higher price than another seller in your market, you must wait for them to make their sales (if any). Once they have made their sales, if there are still buyers who wish to buy at your price, these buyers will buy from you.

If you and another seller in your market submit identical prices, the computer determines the number of buyers who wish to buy units at your common price. If there are "extra" units that cannot be divided evenly among the sellers who submitted the same price, the "extra" unit(s) is (are) randomly awarded by the computer.

Example: Say you and another seller both submit the same price and that 5 buyers are willing to buy units at that price. You and the other seller will each sell 2 units and the 5th or "extra" unit will be randomly awarded to either you or the other seller. You and the other seller will each have a 50/50 chance of selling the "extra" unit.

The Innovation stage determines whether you sell in the Standard or a New product market.

\section{$\underline{\text { Summary of How Units Are Sold }}$}

If you sell a New product:

You sell until you have sold 4 units, or

You sell until your price is greater than any remaining buyer's buyer value

If you sell the Standard product and your price is the lowest:

You sell until you have sold 4 units, or

You sell until your price is greater than any remaining buyer's buyer value

If you sell the Standard product and your price is not the lowest:

You wait until any other sellers (with lower prices) have made their sales, then the process is the same as above

If you sell the Standard product and your price is the same as another seller's:

The computer calculates the number of buyers who wish to buy at your common price. If there are "extra" units that cannot be divided evenly among the sellers who submitted the same price, the computer will randomly determine who sells the extra units

$\underline{\text { Innovation Stage }}$ 
In the Innovation stage you and the other sellers will each independently make choices that determine whether you sell in the Standard product market or in a New product market during the current period.

The product (Standard or New) you will produce in the current period is determined by a random process. This process involves 100 numbers, the integers from 1 to 100 (i.e. 1,2,3,.,98,99,100). Each of these numbers is equally likely to be selected by the process. In other words, the probability of any one number, say 43 , being selected by the process is $1 / 100$ or $1 \%$.

The process just described has two outcomes: success and failure. Success occurs when the process selects either 1, 2, 3, 4, or 5 [a number between 1 and 15 (including both 1 and 15)]; failure occurs when the process selects another number (i.e. a number from $6-100[16-100]$ ). Since the probability that the process will select a number between 1 and 5 [15] is $5 / 100$ [15/100] or $5 \%$ [15\%], the probability that the process results in success is $5 / 100[15 / 100]$ or $\mathbf{5 \%}[\mathbf{1 5 \%}]$.

If the outcome of the process is success, you have developed a new product and will sell this product in a New product market during the current period's Market stage. Otherwise, you will sell the standard product in the Standard product market in the current period.

During each Innovation stage, you will be asked to select the number of innovation processes you wish to undertake in the current period. You may attempt any number of processes between 0 and 20 .

It is important to reiterate that even if you attempt a large number of processes, success is not guaranteed because each process has an independent 5\% [15\%] chance of success.

The potential benefit of choosing at least one process is the chance of getting to sell a New product in the current period. However, innovation processes are not costless. Each attempt costs \$0.10. Regardless of how many $\$ 0.10$ processes you purchase, the probability of success of any one process is $5 \%$ [15\%].

You will choose the number of processes you wish to purchase (if any) before the outcome of each process is randomly determined. If you buy multiple attempts and are successful with your first attempt, you must still pay for the total number of processes you selected.

More than one seller may successfully develop a new product in a given period. However, when sellers successfully develop a new product, they develop unique new products. So sellers who successfully develop a new product do not have to compete with other sellers to sell this new product.

Note that selling a New product may result in a higher profit than selling the Standard product.

After each Innovation stage, you will learn how much the other sellers in your market spent on innovation processes and they will learn how much you spent. You will also learn whether the other sellers were successful in developing a new product or not, and vice versa.

\section{$\underline{\text { Profit }}$}

Your profit in a particular period is calculated as follows.

\section{If you sell between 0 and 3 units:}

$$
\text { Profit }=(\text { Your Price }-\$ 8.15) \cdot(\text { Number of Units Sold })-(\$ 0.10) \cdot(\text { Processes Bought })
$$

\section{If you sell 4 units:}

$$
\text { Profit }=(\text { Your Price }-\$ 8.15) \cdot(3)+(\text { Your Price }-\$ 8.25) \cdot(1)-(\$ 0.10) \cdot(\text { Processes Bought })
$$

Note that in all cases, your profit increases in your price and in the number of units you sell. Your profit decreases (by $\$ 0.10$ ) with each innovation process you buy.

The computer will calculate your profit for you. After each Market stage you will receive feedback about your profit. You will not receive information about the profit of the other sellers in your market, nor will they receive any feedback about your profit. 
At the end of each period your profit (calculated according to the above formula) is added to the profit you have previously earned. The result is referred to as your total profit.

If your total profit dips below $\$ 0.00$, the computer will not let you lose additional money. However, if you have $\$ 0.00$ in total profit you will not be able to purchase any processes in the Innovation stage.

You will be paid your cumulative earnings for all 25 periods at the conclusion of the experiment.

\section{Additional Instructions}

If the other 3 sellers in your market are each successful at developing a New product, and you are not (you are the only seller who will sell in the Standard product market), your price will automatically be set to the lowest allowable price: $\$ 8.25$.

If there are 2,3 , or 4 sellers in the Standard market, then each will submit prices, and sales will be determined according to the instructions given in the Market stage section.

In the first period you will be given an endowment of $\$ 4.00$. This endowment is provided to allow you to buy innovation processes in the first period if you so choose. You are under no obligation to buy processes in the first nor in any subsequent period. If you wish, you can go the entire experiment without buying any innovation processes. If you do so, your endowment will be part of your earnings paid to you at the experiment's conclusion.

You will remain in the same group of four sellers throughout the experiment. Thus, the other sellers in your group in Period 1 will be the other sellers in your group in all subsequent periods. In other words, Seller 2 in Period 1 of the experiment will be Seller 2 in periods 2-25 as well.

\section{Review}

In Innovation stages you choose a number of processes. Processes cost $\$ 0.10$. Each process has an independent 5/100 [15/100] or 5\% [15\%] chance of success. If successful, you sell a New product in that period. Unsuccessful sellers sell the Standard product in that period.

In Market stages you choose a price. In the Standard product market, buyers will buy from you first if your price is less than the other sellers' prices. In a New product market, you are the only seller. In both market types, buyers buy a unit from you if your price is less than their buyer value. 